\title{
Cтатьи
}

\section{РОЛЬ ИНДИВИДУАЛЬНЫХ ЦЕННОСТЕЙ И МОТИВАЦИИ В ЛИТЕРАТУРНОЙ ПРОДУКТИВНОСТИ ПОЭТОВ И ПРОЗАИКОВ}

\author{
М.А. БУЛЬЦЕВА ${ }^{\text {a }}$ Н.М. ЛЕБЕДЕВА ${ }^{\mathrm{a}}$ \\ ${ }^{a}$ Национальный исследовательский университет «Высшая школа экономики», 101000, Россия, \\ Москва, ул. Мясниикая, д. 20
}

\begin{abstract}
Резюме
Цель данного исследования состоит в идентификации различий в факторах, связанных с творческой продуктивностью в разных микродоменах литературной креативности (написание прозы и поэзии). Проводится анализ взаимосвязей между индивидуальными ценностями (по Ш. Шварцу), мотивацией (по Э. Деси и Р. Райану) и творческой продуктивностью у поэтов и прозаиков, измеряемыми по частотному принципу. Выборка состояла из 240 представителей «малой креативности» (на уровне хобби), занимавшихся написанием прозы и/или поэзии в течение последнего года. В эмпирическом исследовании были использованы следующие методики: PVQ-R Ш. Шварца для измерения индивидуальных ценностей; авторский опросник на частоту написания прозы и поэзии, основанный на СBI С. Доллингера; опросник, измеряющий мотивацию креативного поведения, основанный на SDT Э. Деси и Р. Райана. Полученные данные анализировались при помощи факторного анализа, t-критерия Стьюдента, регрессионного анализа и путевого анализа. Было выявлено, что непрофессиональные «поэты» и «прозаики» различаются ценностными приоритетами: у «поэтов» сильнее выражены ценности социального фокуса, а у «прозаиков» - ценности личностного фокуса. Они различаются также набором предикторов творческой литературной продуктивности: так, литературной продуктивности «поэтов» способствуют ценности Открытости изменениям и препятствуют ценности Самопреодоления; а литературной продуктивности «прозаиков» способствуют ценности Сохранения и препятствуют ценности Самопреодоления и Самоутверждения. В исследовании также была определена медиативная роль автономной мотивации во взаимосвязях ценностей с литературной продуктивностью в обеих группах. Таким образом, проведенное исследование раскрывает эвристический потенциал дифференцированного подхода к творческой деятельности посредством изучения креативности на уровне микродоменов.
\end{abstract}

Ключевые слова: креативность, литературное творчество, творческая продуктивность, индивидуальные ценности, мотивация.

Статья подготовлена в результате проведения исследования в рамках Программы фундаментальных исследований Национального исследовательского университета «Высшая школа экономики» (НИУ ВШЭ) с использованием средств субсидии в рамках государственной поддержки ведущих университетов Российской Федерации «5-100». 


\section{Введение}

Креативность, часто рассматриваемая российскими психологами в контексте творческих способностей (Яголковский, 2007), а в западной школе определяемая как создание продукта, полезного и нового с точки зрения социального контекста (Batey, 2012), имеет важнейшее значение в эволюционном развитии человечества (Runco, 2004). Несколько тревожными кажутся результаты исследований, показывающие, что в последние десятилетия во многих сферах наблюдается спад креативности. Так, например, в соответствии с многолетними замерами креативности в США, выполненными на многотысячных выборках, в 1998 и 2008 гг. по сравнению с 1990 г. снизились оригинальность генерируемых идей и продуктивность, несколько упала также и мотивация к творческой деятельности (Kyung, 2011). Примечательно, что, как оказалось, спад наблюдается не во всех сферах реализации креативности. Например, он действительно фиксируется в области литературного творчества, но не в визуальных искусствах (Weinstein et al., 2014).

При этом креативность долгое время являлась и до сих пор остается достаточно дискуссионным объектом исследований в силу своей многоаспектности. После многолетних споров о сущности креативности и введения в оборот понятий, охватывающих разные ее аспекты, в центре внимания оказались вопросы ее дифференцируемости и ее предикторов. В самом общем виде можно определить три основных подхода к рассмотрению «множественности» креативности: как неделимой, универсальной способности; выделение в креативности универсальной и дифференцированной частей; как качества, дифференцированного для разных доменов (Бушина, Лебедева, 2014). Последний подход зарекомендовал себя как наиболее удачный с точки зрения практической применимости (Baer, 1994, 1996). Кроме того, он позволяет более детально концептуализировать креативность, следуя «от общего к частному». Так, данный подход, реализованный в модели креативности Дж. Баера и Дж. Кауфмана (Baer, Kaufman, 2005), позволил определить, что, несмотря на необходимые для актуализации креативности единые условия (например, уровень интеллекта), креативность к ним не сводится и дифференцируется на отличные друг от друга домены и более узкие направления творческой деятельности - микродомены (микродомен - конкретизированный, практически сведенный до специфических заданий уровень творческой деятельности), а потому данный подход является наиболее приемлемым при изучении креативности людей, занимающихся литературной - поэтической и прозаической - деятельностью (далее «поэтов» и «прозаиков» соответственно).

При этом сам анализ может идти на разных уровнях креативности (Kaufman, Beghetto, 2009): на уровне мини-креативности, связанной с новыми и лично значимыми интерпретациями, идеями и представлениями человека (интроспективная и субъективная сторона креативности) (Helfand et al., 2016); на уровне «малой креативности», представляющей собой непрофессиональное и повседневное творчество, которое может осуществляться ежедневно для самовыражения и адаптации к изменениям (Hennesey, Amabile, 2010); 
на уровне профессиональной креативности, фокусирующейся на людях, которые профессионально занимаются той или иной творческой деятельностью (Kaufman, Beghetto, 2009); и, наконец, на уровне большой креативности, связанной с существенно влияющими на общество и культуру креативными достижениями (Hennesey, Amabile, 2010). Однако случаи «большой креативности» не встречаются повсеместно и использование только их в рамках изучения креативности накладывает существенные ограничения на валидизацию результатов, а также способствует распространению стереотипов, что творчество - удел очень небольшого количества выдающихся людей (Beghetto, Kaufman, 2007). В данном исследовании анализ проводится на уровне «малой креативности», т.е. на уровне непрофессионального литературного творчества, воплощающегося в том или ином литературном продукте.

Значение имеет также то, как именно операционализируется и измеряется креативность в каждом конкретном случае: применяется ли качественный или количественный анализ, оценка продуктов, характеристики творческой личности или процесса, самооценка или оценки экспертов. В данном исследовании, как следует из названия, применяется количественный подход, измеряющий частоту креативного поведения (так называемую продуктивность творчества). В соответствии с подходом Дж. Гилфорда (Guilford, 1967) креативность характеризуется сразу несколькими показателями, очень важным является количество генерируемых идей. Эта мысль развивается в работах современных исследователей, использующих «беглость идей» для разработки нового типа инструментов измерения креативности (Sharma, Rastogi, 2009). Было показано, что этот тип измерений, по факту обращенный не столько к самой креативности, согласно ее классическому определению, сколько к продуктивности творческого поведения, является «наиболее надежным методом определения креативных личностей» (Hocevar, 1981), а показатели по нему позитивно коррелируют с другими способами измерения креативности (Jauk et al., 2014; Agnoli et al., 2016). Кроме того, творческая продуктивность напрямую взаимосвязана с мотивационными факторами, в итоге воплощающимися в частоте конкретного творческого поведения.

Необходимо отметить, что исследований на уровне микродоменов на любом уровне креативности с любым способом ее операционализации чрезвычайно мало. И данная работа представляет собой попытку проверить на примере литературной креативности, есть ли смысл углубляться в исследовании креативности, по крайней мере в контексте ее количественной характеристики, и ее предикторов на уровень микродоменов. Чтобы выявить целесообразность изучения микродоменов, обратимся к предикторам креативности и творческой продуктивности и посмотрим, одинаковое ли влияние оказывают связанные с ними факторы на творческую продуктивность в рамках создания прозаических и поэтических литературных произведений. При этом важно отметить, что в соответствии с используемым подходом (Baer, Kaufman, 2005) фактором, определяющим выбор определенного микродомена (а значит, и частоту творческого поведения в нем), является мотивационная составляющая. Это соответствует сложившейся в современных исследованиях 
идее о приоритетном внимании к индивидуальным ценностям и мотивации при рассмотрении предикторов креативности. Представляя ценности как мотивационные триггеры (Feather, 1992), стоит также принять во внимание и типы мотивации, способные играть роль независимого предиктора и выступать в роли посредника между ценностями и поведением (Parks-Leduc, Guay, 2009), в частности творческим поведением.

Индивидуальные ценности, определяемые как трансситуативные цели, различающиеся по важности и служащие в качестве руководящих принципов в жизни людей (Schwartz, 2012), рассматриваются исследователями в качестве предикторов креативности и творческой продуктивности (Dollinger et al., 2007; Kasof et al., 2007), при этом теоретически и методологически ценности часто рассматриваются как каузально связанные с поведением (например, было доказано, что ценности влияют на политическую активность при голосовании - Leimgruber, 2011). Относится это и к творческому поведению (Лебедева, Бушина, 2015). Система ценностей в обновленной теории Шварца это упорядоченный круговой континуум (рисунок 1). Соседние ценности совместимы или нейтральны, а противолежащие противоречат друг другу. Объединяясь, 19 индивидуальных ценностей образуют 4 ценности высшего порядка: Открытость изменениям, Самоутверждение, Сохранение, Самопреодоление, а далее метаценности личностного или социального фокуса (Шварц и др., 2012).

У более творчески продуктивных людей сильнее выражены такие ценности, как самостоятельность, стимуляция, благожелательность, слабее - традиция, безопасность и конформность. Однако разные ценности в разной степени значимы для творческой продуктивности и креативности в целом в рамках отдельных доменов (Dollinger et al., 2007; Kasof et al., 2007; Sousa,

Рисунок 1

Круговой мотивационный континуум 19 ценностей (Шварц и др., 2012)

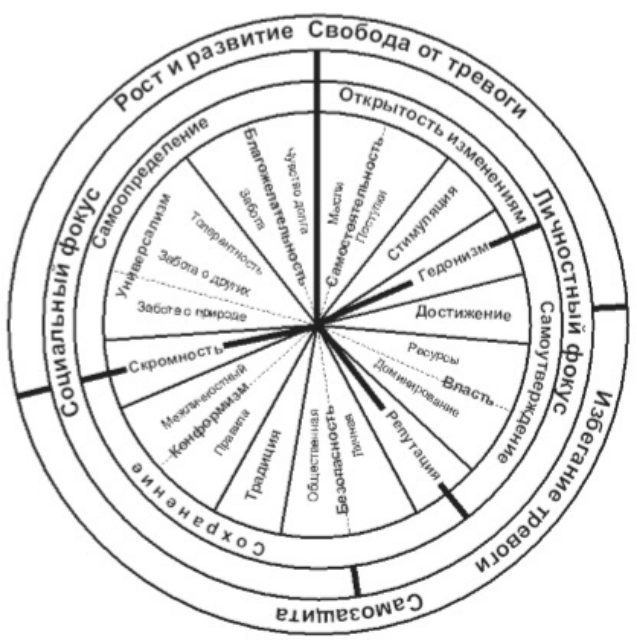


Koelho, 2011). Так, ценности Открытости изменениям позитивно, а ценности Сохранения негативно влияют на литературную творческую продуктивность (Черкасова, 2013; Лебедева, Бушина, 2015).

Мотивация - движущая сила, инициирующая поведение, - также рассматривается как предиктор креативности, в том числе творческой продуктивности. В теории самодетерминации Э. Деси и Р. Райана выделяют пять мотивационных регуляций, которые можно сгруппировать в три типа мотивации (Лебедева, Бушина, 2015) по тому, что́ (цель) или кто именно инициирует мотивирующие воздействия. Первая - контролируемая мотивация, связанная с факторами, внешними по отношению к деятельности и самому человеку, и включающая стороннюю (external) регуляцию поведения, например награда, общественное одобрение или наказание, и интроецированную (introjected) регуляцию, связанную с межличностными отношениями и их последствиями, например обязанностями, долгом, виной, стыдом и тревогой (по Э. Деси и Р. Райану). Вторая - автономная мотивация, связанная с факторами, внутренними по отношению к человеку, она включает в себя идентифицированную (identified) (присваивание мотива, установок и предпочтений) и интегрированную (integrated), (объединяющую важные жизненные цели и ценности) регуляции (по Э. Деси и Р. Райану). Третья - внутренняя мотивация, связанная с факторами, внутренними по отношению к деятельности, и получением удовольствия от нее (Deci, Ryan, 2000). Так как автономная мотивация включает в себя регуляции, связанные с интернализированными целями (Ibid.), именно она - главный претендент на роль посредника между ценностями и креативностью. Следует отметить и опосредующую роль внутренней мотивации в отношениях Открытости изменениям и креативности (Prabhu et al., 2008), ведь между этой чертой личности и ценностями Открытости изменениям существует сильная связь (Roccas et al., 2008).

Нас интересует, различаются ли «поэты» и «прозаики» в ценностных приоритетах и как разные типы мотивации опосредуют влияние ценностей на творческую продуктивность в качестве важной характеристики креативного поведения. Хотя предыдущими исследованиями установлено, что разные ценности взаимосвязаны с креативностью и творческой продуктивностью в разных доменах, однако взаимоотношения ценностей, мотивации и творческой продуктивности на уровне микродоменов пока не известны, что и составляет проблему настоящего исследования. Цель исследования состоит в том, чтобы идентифицировать различия в ценностях и типах мотивации, связанных с литературной продуктивностью поэтов и прозаиков, а также определить роль мотивации в отношениях между ценностной сферой и продуктивностью в различных типах литературной креативности.

Ранее было выявлено, что в поэзии наблюдается недостаточно ясное разделение между субъектом и объектами творчества, в то время как проза связана с «наличием повествовательного самосознающего субъекта, который отделен от объекта творчества и имеет более реалистичное и интегративное отношение к нему» (Forgeard et al., 2013). Более того, анализ существующих исследований показал, что продукт поэтического творчества ориентирован социально 
в большей степени, чем проза. В частности, считается, что поэзия в отличие от прозы, в первую очередь, связана не с сюжетом, а с отражением чувств автора и разделением их с другими людьми; сам процесс написания и создания смысла рассматривается как сотворчество (Волькенштейн, 1970; Оганесян, 2013). Более того, поэзия, воспринимаемая читателями как более сложный вид творчества, является лучшим инструментом аттракции, чем проза (Lange, Euler, 2014). Согласуются с этим и высказывания известных поэтов: например, B. Маяковский говорил, что поэт должен чувствовать настроение людей, быть ориентированным на то, чем общество живет в данный момент и что ему требуется (Маяковский, 1959). Напротив, люди, вовлеченные в написание прозы, склонны рассматривать своего идеального читателя как человека, очень похожего на них во взглядах, который не будет генерировать новые смыслы на основании их посыла, но увидит то же самое, что хотел выразить автор (Michael, 2016). На наш взгляд, подобные различия могут влиять на ценностные приоритеты поэтов и прозаиков. Также считается, что к поэзии более склонны в юности, а к прозе - в зрелости (Blumrosen-Sela, 2002; Lange, Euler, 2014). Так как ценностные приоритеты меняются с возрастом (Schwartz, 2006), то ценности Открытости изменениям и Самоутверждения могут играть важную роль в креативности «поэтов», а ценности Сохранения и Самопреодоления - в креативности «прозаиков». То, что даже писательское сообщество разделяет стереотипы об обреченности литераторов на бедность (Rettig, 2011), хотя проза - более коммерциализированная сфера, может сказаться на взаимосвязях литературной креативности и ценностей Самоутверждения. Из-за более жестких правил поэзия считается более «чистым» и сложным видом творчества, она связана с более короткими сроками и акцентом на эмоциях и ассоциациях, а не на сюжете (Blumrosen-Sela, 2002; Forgeard et al., 2013), что может приводить к различиям во влиянии ценностей Сохранения и Открытости изменениям на креативность в этих микродоменах.

Многочисленные исследования показали, что мотивация связана с творчеством и творческой продуктивностью, но отношения эти разнятся в зависимости от подхода к креативности или определенного домена. Так, внутренняя мотивация имеет значимые положительные корреляции с литературной креативностью (Jesus et al., 2013; Sternberg, 2006). При этом влияние внешней мотивации неоднозначно, начиная с негативного (Amabile, 1985) и до исключительно положительного (Boice, 1983; Eisenberger, Rhoades, 2001). Но если мы посмотрим на процедуру и дизайн исследований, то увидим, что в исследовании Т. Амабайл литературную креативность измеряли через написание стихов, в то время как в других исследованиях использовали написание прозы. В контексте влияния мотивации следует также учесть и бо́льшие возможности коммерциализации своих креативных продуктов у «прозаиков» даже на уровне «малой», а не профессиональной креативности. Кроме того, с творческой продуктивностью в обеих группах может коррелировать автономная мотивация, так как именно она связана с самоидентификацией и реализацией своих ценностей и целей, являясь как предиктором, так и посредником в отношениях ценностей и творческой продуктивности. 


\section{Гипотезы исследования}

В результате анализа были сформулированы следующие гипотезы.

Гипотеза 1. Приоритеты индивидуальных ценностей «поэтов» и «прозаиков» различны: у «прозаиков» более выражены ценности личностного фокуса (ценности Открытости изменениям и Самоутверждения) и менее выражены ценности социального фокуса (ценности Сохранения и Самопреодоления), чем у «поэтов».

Гипотеза 2. Различные наборы ценностей связаны с творческой продуктивностью у «поэтов» и «прозаиков»:

$2 a$. Ценности Открытости изменениям и Самопреодоления связаны положительно, а ценности Самоутверждения отрицательно с литературной творческой продуктивностью «поэтов»;

26. Ценности Самоутверждения связаны положительно, а ценности Сохранения и Самопреодоления отрицательно с литературной творческой продуктивностью «прозаиков».

Гипотеза 3. Литературная творческая продуктивность «поэтов» и «прозаиков» связана с разными видами мотивации:

3a. Литературная творческая продуктивность «поэтов» связана отрицательно с контролируемой мотивацией и положительно с автономной и внутренней мотивацией;

3б. Литературная творческая продуктивность «прозаиков» связана положительно с контролируемой, автономной и внутренней мотивацией.

Гипотеза 4. Мотивация опосредует отношения между индивидуальными ценностями и литературной творческой продуктивностью:

4a. Автономная мотивация опосредует отношения между индивидуальными ценностями и литературной творческой продуктивностью;

46. Внутренняя мотивация опосредует отношения между ценностями Открытости изменениям и литературной творческой продуктивностью.

\section{Методика исследования}

\section{Участники исследования}

Выборка состояла из 240 представителей «малой креативности» (повседневная креативность и хобби, а не профессиональная деятельность - определялась по отрицательному ответу на вопрос о том, зарабатывает ли респондент деньги профессиональным написанием поэтических или прозаических художественных текстов), писавших прозу и/или поэзию на русском языке в течение последнего года: 118 «поэтов» (31 мужчина, 87 женщин, средний возраст - 22.6) и 122 «прозаика» (32 мужчины, 90 женщин, средний возраст - 22.8), публиковавшихся в Интернете на специализированных площадках и, таким образом, включенных в пишущее сообщество (а значит, имеющих возможность испытать на себе влияние всех рассматриваемых типов мотивации). При этом респондент относился к «прозаикам», если в 
соответствующем вопросе опросника давал ответ, что за последний год чаще писал прозу, и это подтверждалось измерениями по частоте его креативного поведения в микродоменах; по аналогичному принципу респондент относился к «поэтам»; данные же тех респондентов, кто затруднялся определить, что он писал чаще (т.е. тех, у кого не было выявлено самоидентификации с одной из групп), или чья частота креативного поведения в микродоменах была приблизительно одинаковой, в анализе не использовались.

\section{Memoдbl}

Использовались методики, построенные по типу шкал Ликерта:

- Обновленный опросник (PVQ-R) Ш. Шварца (Шварц и др., 2012), измеряющий 19 ценностей и включающий 57 пунктов - портретных описаний (например, «Для него важно расширять свой кругозор»), степень сходства каждого из которых с собственными чертами респонденту предлагалось оценить по шкале Ликерта от 1 - «Очень похож на меня» до 6 - «Совсем не похож на меня» (при обработке результаты по шкалам были перевернуты). Согласно теории Шварца, данные ценности группируются в ценности-оппозиции более высокого порядка: Сохранение $(\alpha=0.75)$ - Открытость изменениям $(\alpha=0.67)$; Самоутверждение $(\alpha=0.77)-$ Самопреодоление $(\alpha=0.77)$.

- Авторский количественный опросник, измеряющий литературную творческую продуктивность через частоту написания прозы и поэзии, разработанный на основе опросника С. Доллингера (Dollinger et al., 2007): из исходного опросника были удалены вопросы, не связанные с литературной креативностью, и добавлены вопросы в соответствии с российской системой литературных жанров. Опросник прошел проверку с помощью когнитивного интервью и факторного анализа (согласованность шкал, измеряющих литературную продуктивность в написании поэзии $-\alpha=0.74$, в написании прозы $-\alpha=0.76$, в целом $\alpha=0.53)$. Опросник состоит из 13 пунктов, представляющих собой описание видов креативного поведения в этих двух микродоменах в соответствии с российской системой литературных жанров. В инструкции респондентов просят выбрать из предложенного списка те деятельности, в которые они были активно включены на протяжении последних 12 месяцев. Для ответа использовалась 4-балльная шкала: 1 - «Никогда не делал», 2 - «Делал один или два раза», 3 - «Делал 3-5 раз», 4 - «Делал больше пяти раз».

- Опросник, измеряющий мотивацию, разработанный в Международной лаборатории социокультурных исследований (МНУЛ СКИ) НИУ ВШЭ на основе теории Э. Деси и Р. Райана (Deci, Ryan, 2000), включающий в себя в качестве вопросов описание мотивационных регуляций по двум видам креативной деятельности. Данный опросник мотивации креативного поведения, разработанный в МНУЛ СКИ на основе теории саморегуляции Деси и Райана (Лебедева, Бушина, 2015: $\alpha=0.72)$, включает в себя два вида поведения и пять причин, объясняющих каждый из этих двух видов поведения (у нас - написание прозы и написание поэзии): причина $1-$ «од воздействием внешних влияний; наград или наказаний», причина $2-$ «Чтобы получить одобрение 
или избежать чувства стыда», причина 3 - «Потому что это важно для меня», причина 4 - «Это свободный выбор после серьезного обдумывания», причина 5 - «Потому что это мне нравится». Оценка причины регуляции производилась с помощью пятибалльной шкалы от 1 - «Совсем не по этой причине» до 5 - «Именно по этой причине». Оценка мотивации креативного поведения производилась с помощью трех шкал, отражающих мотивацию поведения в соответствии с теорией Деси и Райана: контролируемую (Причина $1+$ Причина 2), автономную (Причина 3 + Причина 4), внутреннюю (Причина 5).

Респонденты также указывали возраст и пол, регион проживания, в какой вид литературной креативности (написание прозы или поэзии) они были больше вовлечены в течение последнего года, зарабатывали ли они деньги профессиональным написанием художественных текстов.

\section{Прочедура}

Опросник был размещен на платформе Qualtrix и заполнялся респондентами индивидуально, без контакта с интервьюером. Среднее время заполнения опросника составило 25 минут.

\section{Результаты}

Данные были обработаны в программах Amos (22 версия) and SPSS (17 версия) при помощи методов: t-критерии Стьюдента для сравнения средних, регрессионный анализ и путевой анализ с оценкой опосредующих эффектов.

Описательные статистики и ценностные приоритеть «поэтов» и «прозаиков»

Сравнение средних (таблица 1) по переменным в разных группах показало, что, хотя общий уровень литературной продуктивности поэтов и прозаиков статистически не различается (а значит, мы можем сравнивать их по другим критериям), их продуктивность в разных микродоменах, а также выраженность индивидуальных ценностей и внутренней мотивации различны.

Гипотеза 1 также проверялась через сравнение средних. Межгрупповое сравнение показало бо́льшую выраженность ценностей социального фокуса и меньшую - личностного фокуса у «поэтов», чем у «прозаиков».

Таким образом, первая гипотеза подтвердилась: действительно, у «поэтов» сильнее выражены ценности социального фокуса (ценности Сохранения и Самопреодоления) и слабее личностного фокуса (ценности Открытости изменениям), чем у «прозаиков».

Взаимосвязь ценностей и литературной продуктивности у «поэтов» и «прозаиков»

Анализ взаимосвязи ценностей и литературной продуктивности проводился при помощи линейного регрессионного анализа и предполагал каузальную 
Таблица 1

Описательные статистики и показатели t-критерия сравнения по основным используемым переменным в группах «поэтов» и «прозаиков»

\begin{tabular}{|l|c|c|c|c|c|c|c|}
\hline \multirow{2}{*}{} & \multicolumn{3}{|c|}{ Поэты } & \multicolumn{3}{c|}{ Прозаики } & \multirow{2}{*}{$\boldsymbol{t}$} \\
\cline { 2 - 8 } & $\mathrm{M}$ & $\mathrm{SD}$ & $\alpha$ & $\mathrm{M}$ & $\mathrm{SD}$ & $\alpha$ & \\
\hline Литературная продуктивность & 1.95 & 0.38 & 0.63 & 2.04 & 0.42 & 0.66 & -1.57 \\
\hline Поэтическая продуктивность & 2.35 & 0.52 & 0.57 & 1.52 & 0.43 & 0.59 & $13.02^{* *}$ \\
\hline Прозаическая продуктивность & 1.55 & 0.37 & 0.36 & 2.55 & 0.59 & 0.59 & $-11.99^{* *}$ \\
\hline Ценности личностногофокуса & 4.37 & 0.34 & 0.75 & 4.52 & 0.63 & 0.71 & $-2.09^{*}$ \\
\hline Ценности социального фокуса & 4.05 & 0.58 & 0.8 & 3.82 & 0.33 & 0.79 & $4.79^{* *}$ \\
\hline Открытость изменениям & 4.72 & 0.59 & 0.66 & 4.91 & 0.58 & 0.67 & $-2.5^{*}$ \\
\hline Самоутверждение & 3.98 & 0.89 & 0.82 & 4.16 & 0.75 & 0.70 & -1.63 \\
\hline Сохранение & 4.19 & 0.85 & 0.79 & 3.92 & 0.83 & 0.72 & $2.47^{*}$ \\
\hline Самопреодоление & 4.65 & 0.65 & 0.77 & 4.42 & 0.69 & 0.76 & $2.44^{*}$ \\
\hline Контролируемая мотивация & 1.43 & 0.54 & 0.49 & 1.46 & 0.65 & 0.37 & -0.35 \\
\hline Автономная мотивация & 3.17 & 1.05 & 0.48 & 3.13 & 1.01 & 0.51 & 0.29 \\
\hline Внутренняя мотивация & 4.35 & 0.85 & & 4.67 & 0.72 & & $-3.18^{* *}$ \\
\hline
\end{tabular}

${ }^{*} p<0.05,{ }^{* *} p<0.01$.

связь на основании предпосылок использованной теоретической модели. Линейный регрессионный анализ (методом enter) связи индивидуальных ценностей и литературной продуктивности у «поэтов» и «прозаиков» (таблица 2) показал, что различные наборы ценностей связаны с литературной продуктивностью в этих группах. У «поэтов» ценности Открытости изменениям способствуют, а ценности Самопреодоления препятствуют литературной продуктивности, а у «прозаиков» ценности Сохранения способствуют, а ценности Самоутверждения и Самопреодоления препятствуют литературной продуктивности.

Таким образом, гипотеза 2 была подтверждена частично: действительно, разные наборы ценностей связаны с литературной продуктивностью у «поэтов» и «прозаиков», однако частные гипотезы о составе этих наборов были подтверждены лишь частично. Так, гипотеза 2a, касающаяся взаимосвязи ценностей и литературной продуктивности в группе «поэтов», подтвердилась только в отношении ценностей Открытости изменениям, а гипотеза 2б, касающаяся взаимосвязи ценностей и литературной продуктивности в группе «прозаиков», подтвердилась только в отношении ценностей Самопреодоления.

\section{Роль мотивации в креативности «поэтов» $и$ «прозаиков»}

Анализ на уровне контролируемой, автономной и внутренней мотивации не обладает высокой прогностической ценностью, регрессионные модели 
Таблица 2

Результаты регрессионного анализа связи ценностей и литературной продуктивности у поэтов и прозаиков

\begin{tabular}{|l|c|c|c|c|}
\hline \multirow{2}{*}{ Группа } & \multicolumn{4}{|c|}{ Ценности } \\
\cline { 2 - 5 } & $\begin{array}{c}\text { Открытости } \\
\text { изменениям }\end{array}$ & Самоутверждения & Сохранения & Самопреодоления \\
\cline { 2 - 5 } & $\beta$ & $\beta$ & $\beta$ & $\beta$ \\
\hline \multirow{2}{*}{$R^{2}$} & $0.39^{* *}$ & $-0.2^{\dagger}$ & -0.05 & $-0.28^{*}$ \\
\hline$F$ & \multicolumn{5}{|c|}{0.13} \\
\hline «Птозаики» & 0.17 & $-0.23^{*}$ & $0.24^{*}$ & $-0.39^{*}$ \\
\hline$R^{2}$ & \multicolumn{5}{|c|}{0.11} \\
\hline$F$ & \multicolumn{5}{|c|}{$3.39^{*}$} \\
\hline
\end{tabular}

${ }^{\dagger} p<0.1,{ }^{*} p<0.05,{ }^{* * *} p<0.01$.

Таблица 3

Результаты регрессионного анализа связи мотивации и литературной продуктивности у «поэтов» и «прозаиков»

\begin{tabular}{|l|c|c|c|}
\hline \multirow{2}{*}{ Группа } & \multicolumn{3}{|c|}{ Тип мотивации } \\
\cline { 2 - 4 } & Контролируемая & Автономная & Внутренняя \\
\cline { 2 - 4 } & $\beta$ & $\beta$ & $\beta$ \\
\hline «Поэты» & 0.1 & $0.19^{\dagger}$ & 0.12 \\
\hline$R^{2}$ & \multicolumn{3}{|c|}{} \\
\hline$F$ & 0.02 & 0.06 & $0.17^{\dagger}$ \\
\hline «Прозаики» & \multicolumn{3}{|c|}{} \\
\hline$R^{2}$ & \multicolumn{3}{|c|}{0.11} \\
\hline$F$ & \multicolumn{3}{|c|}{1.9} \\
\hline
\end{tabular}

${ }^{\dagger} p<0.1$.

(линейный регрессионный анализ методом одновременного включения) для обеих групп статистически незначимы (таблица 3). Но на уровне тенденции у «поэтов» автономная мотивация $(p=0.05)$, а у «прозаиков» внутренняя мотивация $(p=0.07)$ способствуют литературной продуктивности.

Общая гипотеза 3 и частные гипотезы За и Зб были опровергнуты результатами регрессионного анализа (так как модели оказались статистически незначимыми). Хотя на уровне тенденции можно говорить о частичном подтверждении этих гипотез. 


\section{Опосредующие эффекты мотивации во взаимосвязи ценностей и литературной продуктивности}

Для проверки гипотезы об опосредующей роли мотивации были построены модели в AMOS 22 (тестируемая модель представлена на рисунке 2), в которых индивидуальные ценности выступали в качестве независимых переменных, типы мотивации - в качестве посредников, а литературная продуктивность - в качестве зависимой переменной.

Был проведен анализ опосредующих эффектов по методу Барона и Кенни (Baron, Kenny, 1986; Kenny, 2015), в соответствии с которым должны быть выполнены четыре шага для идентификации посредника: 1) проверить, существует ли связь между зависимой и независимой переменными; 2) проверить, существует ли связь между независимой переменной и посредником; 3) проверить, существует ли связь между зависимой и независимой переменными при включении в модель посредника; 4) оценить прямые и косвенные эффекты. В соответствии с первым шагом для анализа опосредующих эффектов в качестве независимой переменной в группе «поэтов» имеет смысл рассматривать ценности Открытости изменениям и Самопреодоления, у «прозаиков» ценности Сохранения, Самоутверждения и Самопреодоления. В соответствии со вторым шагом (таблица 4) в качестве посредника в группе «поэтов» имеет смысл рассматривать автономную и внутреннюю мотивации, а в группе «прозаиков» - все три типа мотивации.

В соответствии с третьим и четвертым шагом были проведены расчеты по частным моделям для групп «поэтов» и «прозаиков». Все модели далее являются адаптациями общей тестируемой модели (рисунок 2), в которых для удобства указаны только статистически значимые связи и стандартизированные коэффициенты.

Рисунок 2

Опосредующая роль мотивации во взаимосвязи ценностей и литературной продуктивности

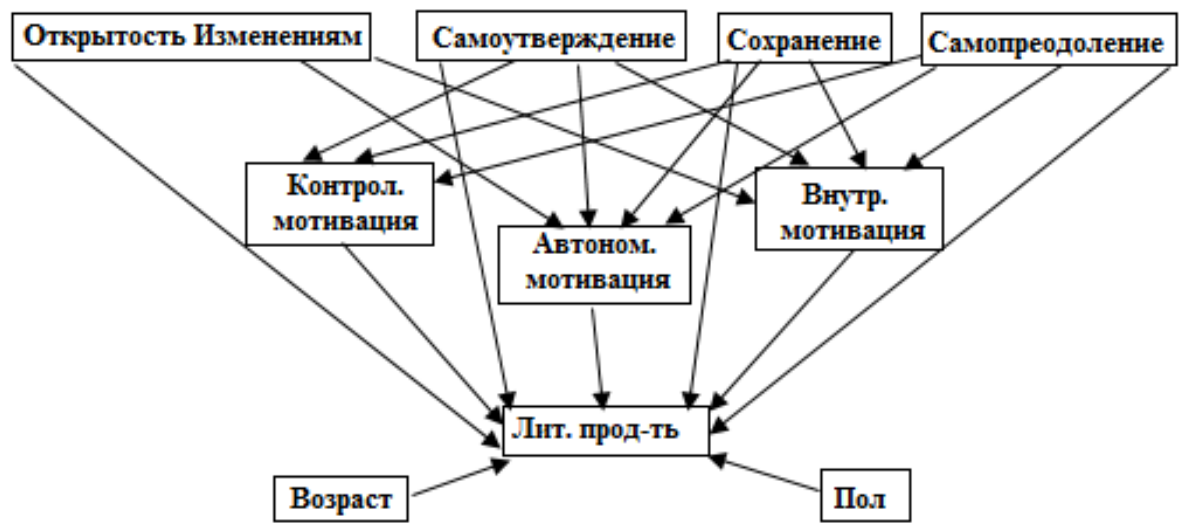


Таблица 4

Результаты регрессионного анализа связи индивидуальных ценностей и мотивации

\begin{tabular}{|l|c|c|c|c|c|c|}
\hline \multirow{2}{*}{} & \multicolumn{3}{|c|}{ «Поэты» } & \multicolumn{3}{c|}{ «Прозаики» } \\
\cline { 2 - 8 } & Контр. & Автон. & Внутр. & Контр. & Автон. & Внутр. \\
\cline { 2 - 8 } & $\beta$ & $\beta$ & $\beta$ & $\beta$ & $\beta$ & $\beta$ \\
\hline Открытость изменениям & -0.07 & $0.26^{*}$ & $-0.3^{*}$ & 0.2 & 0.2 & -0.03 \\
\hline Самоутверждение & 0.09 & -0.13 & $-0.25^{*}$ & 0.1 & -0.07 & $-0.24^{*}$ \\
\hline Сохранение & 0.09 & $0.32^{* *}$ & 0.13 & $0.03^{*}$ & $0.22^{*}$ & 0.12 \\
\hline Самопреодоление & 0.01 & 0.00 & 0.06 & $-0.34^{*}$ & 0.06 & 0.07 \\
\hline$R^{2}$ & 0.02 & 0.16 & 0.08 & 0.8 & 0.1 & 0.08 \\
\hline$F$ & 0.54 & $5.08^{* *}$ & $2.56^{*}$ & $3.65^{* *}$ & $3.39^{*}$ & $2.56^{*}$ \\
\hline
\end{tabular}

${ }^{*} p<0.05,{ }^{* * *} p<0.01$.

Рисунок 3

Опосредующая роль мотивации во взаимосвязи ценностей и креативности у «поэтов»

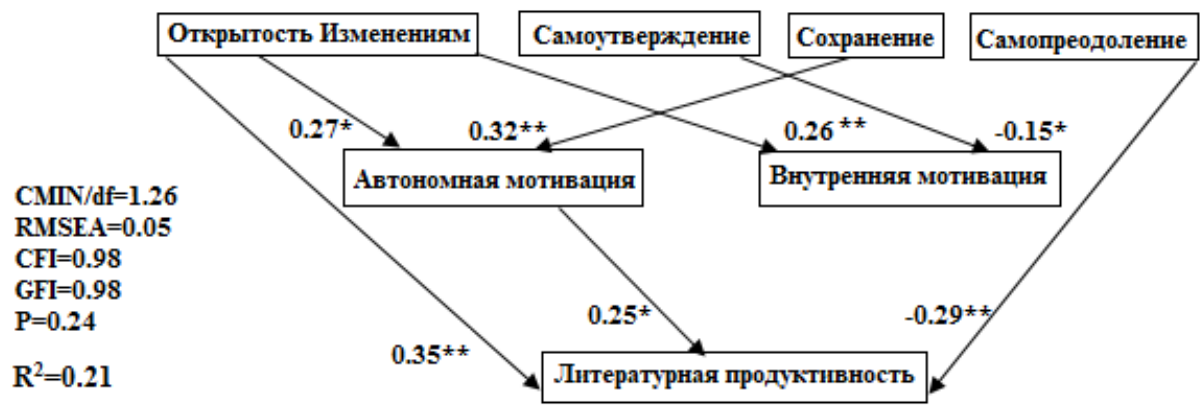

$\mathrm{y}$ «поэтов» (рисунок 3) автономная мотивация частично опосредует эффект, оказываемый ценностями Открытости изменениям на литературную продуктивность (таблица 5). При этом, несмотря на то, что на представленном рисунке прослеживается связь: ценности Сохранения - автономная мотивация - литературная продуктивность, здесь мотивация не является посредником в соответствии с пунктом 1 метода Барона и Кенни.

$\mathrm{Y}$ «прозаиков» (рисунок 4) автономная мотивация полностью опосредует взаимосвязь между ценностями Сохранения и литературной продуктивностью (таблица 6). При этом, несмотря на то, что на рисунке прослеживается связь: ценности Самоутверждения - внутренняя мотивация - литературная продуктивность, здесь мотивация не является посредником в соответствии с пунктом 4 метода Барона и Кенни (не был обнаружен статистически значимый косвенный эффект). 
Таблица 5

Опосредующий эффект мотивации в группе «поэтов»

\begin{tabular}{|c|c|c|c|c|}
\hline \multirow{3}{*}{ Путь } & \multirow{2}{*}{$\begin{array}{l}\text { Модель без } \\
\text { посредника }\end{array}$} & \multicolumn{3}{|c|}{ Модель с посредником } \\
\hline & & Полный эффект & Прямой эффект & Косвенный эффект \\
\hline & $\beta$ & $\beta$ & $\beta$ & $\beta$ \\
\hline $\begin{array}{l}\text { Открытость } \\
\text { изменениям } \rightarrow \\
\text { автономная } \\
\text { мотивация } \rightarrow \\
\text { литературная } \\
\text { продуктивность }\end{array}$ & $0.39 * *$ & $0.4^{* *}$ & $0.35^{* *}$ & $0.06^{*}$ \\
\hline
\end{tabular}

$* p<0.05, * * * p<0.01$.

Рисунок 4

Опосредующая роль мотивации во взаимосвязи ценностей и креативности у «прозаиков»

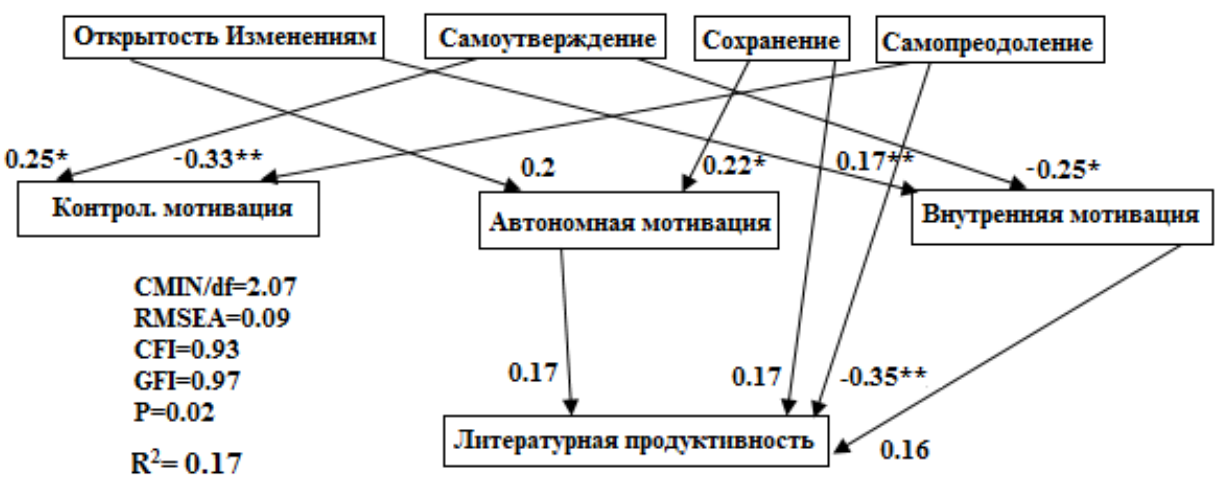

Таблица 6

Опосредующий эффект мотивации в группе «прозаиков»

\begin{tabular}{|l|c|c|c|c|}
\hline \multirow{2}{*}{\multicolumn{1}{|c|}{ Путь }} & \multirow{2}{*}{$\begin{array}{l}\text { Модель без } \\
\text { посредника }\end{array}$} & \multicolumn{3}{|c|}{ Модель с посредником } \\
\cline { 2 - 5 } & $\beta$ & $\beta$ & $\beta$ & $\beta$ \\
\hline $\begin{array}{l}\text { Сохранение } \rightarrow \\
\text { автономная } \\
\text { мотивация } \rightarrow \\
\begin{array}{l}\text { литературная } \\
\text { продуктивность }\end{array}\end{array}$ & $0.24^{*}$ & 0.21 & 0.17 & $0.05^{*}$ \\
\hline $\begin{array}{l}\text { Самоутверждение } \rightarrow \\
\text { внутренняя } \\
\begin{array}{l}\text { мотивация } \rightarrow \\
\text { литературная } \\
\text { продуктивность }\end{array}\end{array}$ & $-0.23^{*}$ & & & \\
\hline
\end{tabular}

${ }^{*} p<0.05, * * * p<0.01$. 
Таким образом, общая гипотеза 4 была подтверждена, как и гипотеза 4а, но опосредующий эффект внутренней мотивации выявлен не был, так что нельзя говорить о подтверждении гипотезы 46.

\section{Обсуждение результатов}

Мы обнаружили разницу в приоритетных ценностях социального и личностного фокуса: у «поэтов» сильнее выражены ценности социального фокуса (ценности Сохранения и Самопреодоления), а у «прозаиков» - личностного (ценности Открытости изменениям). Различие в ценностях Самоутверждения между группами было статистически незначимым, что, возможно, связано с тем, что в выборку были включены представители малой, а не профессиональной креативности. Эти результаты могут объясняться особенностями микродоменов креативности: поэзия более ориентирована на правила и социум, но в то же время и более ограничена в возможностях для личного самоутверждения, чем проза. Также данный результат соответствует используемому подходу к креативности - в модели Баера и Кауфмана (Baer, Kaufman, 2005) мотивационный базис (в нашем понимании - ценности как его составляющая) служит причиной выбора определенного микродомена креативности и проявления определенного творческого поведения.

Мы определили, что литературной продуктивности «поэтов» способствуют ценности Открытости изменениям и препятствуют ценности Самопреодоления; а литературной продуктивности «прозаиков» способствуют ценности Сохранения и препятствуют ценности Самопреодоления и Самоутверждения. Полученные результаты интересны еще и в связи с выявленными приоритетами ценностей - для креативности наиболее значимыми оказались не те ценности, которые в приоритете: так, например, среди «прозаиков», более ориентированных на ценности личностного профиля, связанными с креативностью оказались две группы ценностей социального профиля и лишь одна личностного. На наш взгляд, подобный результат может быть связан как с обобщенным концептом литературной продуктивности (одновременно и написание прозы, и написание поэзии), так и с общим выявленным в социальной психологии феноменом ценностей - передаются последующим поколениям и влияют на установки и поведение в большей степени не наиболее, а наименее выраженные ценности (Boehnke et al., 2007; Grigoryan et al., 2018).

Говоря о статистической незначимости взаимосвязи типов мотивации с креативностью, нужно помнить о том, что размеры выборок были весьма невелики для регрессионного анализа и что использовалась нетрадиционная группировка на три типа мотивации. На уровне тенденции выявлено, что автономная мотивация способствует литературной продуктивности «поэтов», а внутренняя - литературной продуктивности «прозаиков». При этом внутренняя мотивация сильнее выражена у «прозаиков», чем у «поэтов». Возможно, это связано с тем, что поэзия - более социально ориентированное творчество, в то время как внутренняя мотивация концентрирует человека на 
собственном удовольствии, а не на других людях и целях, интернализируемых на уровне автономной мотивации.

Также мы выяснили, что взаимосвязи ценностей Открытости изменениям и Сохранения с литературной продуктивностью опосредуются автономной мотивацией, но в зависимости от микродомена креативности.

Таким образом, различия между микродоменами литературной креативности несколько глубже, чем принято считать, и уходят на уровень индивидуальных ценностей и их взаимосвязи с поведением. Для более глубокого понимания сущности человеческой креативности и ее предикторов, по-видимому, имеет смысл углубляться в исследовании креативности на уровень микродоменов.

К ограничениям данного исследования относятся структура (только представители «малой креативности») и небольшой размер выборки; обобщенный концепт литературной продуктивности в расчетах, количественный подход к креативности, а также относительная культурная однородность выборки. В будущем стоит рассмотреть взаимосвязь ценностей и мотивации не просто с литературной продуктивностью, но конкретно с написанием прозы или поэзии или с их соотношением в литературной креативности пишущих людей. Кросс-культурный анализ может выявить влияние культурной среды на исследуемые феномены.

\section{Литература}

Бушина, Е. В., Лебедева, Н. М. (2014). Изучение креативности в разных сферах. В кн. В. Гриценко (ред.), Теоретические проблемы этнической и кросс-культурной психологии: Материаль Четвертой международной научной конференции 30-31 мая 2014 г. (т. 1, c. 158-161). Смоленск: Смоленский гуманитарный университет.

Волькенштейн, М. (1970). Стихи как сложная информационная система. Наука и жизнь, 1. Режим доступа: http://www.lib.ru/NTL/ARTICLES/volkernsht.txt_with-big-pictures.html

Лебедева, Н. М., Бушина, Е. В. (2015). Влияние ценностей и мотивации личности на креативное поведение и отношение к инновациям. Психология в экономике и управлении, 7(1), 26-35. doi: 10.17150/2225-7845.2015.7(1).26-35

Маяковский, В. В. (1959). Как делать стихи. В кн. В. В. Маяковский, Полное собрание сочинений (т. 12, с. 81-117). М.: Художественная литература. Режим доступа: http://febweb.ru/feb/mayakovsky/texts/ms0/msc/msc-081-.htm

Оганесян, Н. Н. (2013). Практикум по психологии творчества. М.: Флинта.

Черкасова, Л. Л. (2013). Сферы креативности и индивидуальные ценности Ш. Шварца. APRIORI. Серия: Гуманитарные науки, 2, 1-20.

Шварц, Ш., Бутенко, Т. П., Седова, Д. С., Липатова, А. С. (2012). Уточненная теория базовых индивидуальных ценностей: применение в России Психология. Журнал Высшей школы экономики, 9(2), 43-70.

Яголковский, С. Р. (2007). Психология креативности и инноваций: учебное пособие. М.: ГУ ВШЭ.

Ссылки на зарубежные источники см. в разделе References после англоязычного блока. 
Бульцева Мария Александровна - аспирант, стажер-исследователь, Международная научно-учебная лаборатория социокультурных исследований, Экспертный институт, Национальный исследовательский университет «Высшая школа экономики».

Сфера научных интересов: психология креативности, кросс-культурная психология.

Контакты: bulceva@mail.ru

Лебедева Надежда Михайловна - заведующая, Международная научно-учебная лаборатория социокультурных исследований, Экспертный институт; профессор, департамент психологии, факультет социальных наук, Национальный исследовательский университет «Высшая школа экономики», доктор психологических наук, профессор.

Сфера научных интересов: этническая и кросс-культурная психология, межкультурные отношения, аккультурация мигрантов, трансмиссия ценностей, креативность и инновации. Контакты: nlebedeva@hse.ru

\title{
The Role of Individual Values and Motivation in Creative Writing Productivity of Poets and Prose Writers
}

\author{
M.A. Bultseva ${ }^{a}$, N.M. Lebedeva \\ ${ }^{a}$ National Research University Higher School of Economics, 20 Myasnitskaya Str., Moscow, 101000, \\ Russian Federation
}

\begin{abstract}
The aim of this study was to identify differences in factors related to productivity in different micro-domains of literary creativity (writing prose and writing poetry). This study examined the relations between values (according to S. Schwartz's approach), motivation types (according to SDT by E. Deci and R. Ryan) and creative writing productivity among "poets" and "writers". The sample consisted of 240 representatives of "little creativity" involved in writing poetry or prose during last year. The research used such questionnaires for data gathering as revised PVQR by S. Schwartz, authors' questionnaire to measure frequency of creative behavior (based on CBI by S. Dollinger) and questionnaire of motivation to creative behavior developed by the HSE International Scientific Socio-Cultural Laboratory on the basis of E. Deci and R. Ryan's questionnaire. We used such methods of data processing as confirmatory factor analysis, T-test for comparing means, regression analyses and path-analysis in AMOS. We revealed that "poets" and "writers" have differences in values and their relations to creativity. For poets Social Focus values were more important than for prose writers, while for prose writers Personal Focus values were more important than for poets. Different sets of values were related to literary creative productivity among "poets" and "writers": Openness to Change and Self-Transcendence values among "poets"; and Conservation, Self-Enhancement and Self-Transcendence values among "prose writers". Autonomous motivation played a mediator role in the relations between values and creativity in both groups. Thus, the conducted research revealed the heuristic potential of the approach differentiating creativity in micro-domains.
\end{abstract}

Keywords: creativity, creative writing, creative productivity, individual values, motivation. 


\section{References}

Agnoli, S., Corazza, G. E., \& Runco, M. (2016). Estimating creativity with a multiple-measurement approach within scientific and artistic domains. Creativity Research Journal, 28(2), 171-176.

Amabile, T. (1985). Motivation and creativity: Effects of motivational orientation on creative writers. Journal of Personality and Social Psychology, 48, 393-399. doi:10.1037//0022-3514.48.2.393

Baer, J. (1994). Divergent thinking is not a general trait: A multidomain training experiment. Creativity Research Journal, 7, 35-46.

Baer, J. (1996). The effects of task-specific divergent-thinking training. Journal of Creative Behavior, 30, 183-187, doi:10.1002/j.2162-6057.1996.tb00767.x

Baer, J., \& Kaufman, J. C. (2005). Bridging generality and specificity: The Amusement Park Theoretical (APT) model of creativity. Roeper Reviewe, 27, 158-163. doi:10.1080/02783190509554310

Baron, R. M., \& Kenny, D. A. (1986). The moderator-mediator variable distinction in social psychological research: Conceptual, strategic and statistical considerations. Journal of Personality and Social Psychology, 51, 1173-1182.

Batey, M. (2012). The measurement of creativity: From definitional consensus to the introduction of a new heuristic framework. Creativity Research Journal, 24(1), 55-65. doi:10.1080/10400419.2012.649181

Beghetto, R. A., \& Kaufman, J. C. (2007). Toward a broader conception of creativity: A case for "mini-c". Psychology of Aesthetics, Creativity, and the Arts, 1(2), 73-79. doi:10.1037/1931-3896.1.2.73

Blumrosen-Sela, S. (2002). Psychoanalytic explanations for the transition of writers from poetry to prose writing. PSYART: A Hyperlink Journal for the Psychological Study of the Arts. Retrieved from http://www.psyartjournal.com/article/show/blumrosen_sela-psychoanalytic_explanations_for_the_tran

Boehnke, K., Hadjar, A., \& Baier, A. (2007). Parent-child value similarity: The role of zeitgeist.Journal of Marriage and Family, 69, 778-792. doi:10.1111/j.1741-3737.2007.00405.x

Boice, R. (1983). Contingency management in writing and the appearance of creative ideas: Implications for the treatment of writing blocks. Behavior Research and Therapy, 21, 537-543. doi:10.1016/0005-7967(83)90045-1

Bushina, E. V., \& Lebedeva, N. M. (2014). Izuchenie kreativnosti v raznykh sferakh [Studing creativity in different domains]. In V. Gritsenko (Ed.), Teoreticheskie problemy etnicheskoi i kross-kul'turnoi psikhologii: Materialy Chetvertoi mezhdunarodnoi nauchnoi konferentsii 30-31 maya 2014 g. [Theoretical problems of ethnic and cross-cultural psychology: Proceedings of the IV International Scientific conference, 30-31 May, 2014] (Vol. 1, pp. 158-161). Smolensk: Smolenskii gumanitarnyi universitet. (in Russian)

Cherkasova, L. L. (2013). Sfery kreativnosti i individual'nye tsennosti Sh. Shvartsa [Domains of creativity and individual values by S. Schwartz]. APRIORI. Seriya: Gumanitamye Nauki, 2, 1-20. (in Russian)

Deci, E. L., \& Ryan, R. M. (2000). Intrinsic and extrinsic motivations: Classic definitions and new directions. Contemporary Educational Psychology, 25, 54-67. doi:10.1006/ceps.1999.1020

Dollinger, S. J., Burke, P. A., \& Gump, N. W. (2007). Creativity and values. Creativity Research Journal, 19, 91-103. doi:10.1080/10400410701395028

Eisenberger, R., \& Rhoades, L. (2001). Incremental effects of reward on creativity. Journal of Personality and Social Psychology, 81(4), 728-741. doi:10.1037//0022-3514.81.4.728

Feather, N. T. (1992). Values, valences, expectations, and actions. Journal of Social Issues, 48, 109-124.

Forgeard, M. J. C., Kaufman, S. B., \& Kaufman, J. C. (2013). The psychology of creative writing. In G. Harper (Ed.), A companion to creative writing (pp. 320-333). Chichester, UK: John Wiley \& Sons, Ltd. doi:10.1002/9781118325759.ch21 
Grigoryan, L. K., Lebedeva, N., \& Breugelmans, S. M. (2018). A cross-cultural study of the mediating role of implicit theories of innovativeness in the relationship between values and attitudes toward innovation. Journal of Cross-Cultural Psychology. Advance online publication. doi:10.1177/0022022116656399

Guilford, J. P. (1967). Creativity: Yesterday, today and tomorrow. The Journal of Creative Behavior, 1, 3-14.

Helfand, M., Kaufman, J. C., \& Beghetto, R. A. (2016). The Four-C Model of Creativity: culture and context. In V. P. Glăveanu (Ed.), The Palgrave handbook of creativity and culture research (pp. 15-36). London, UK: Palgrave Macmillan.

Hennessey, B. A., \& Amabile, T. B. (2010). Creativity. Annual Review of Psychology, 61, 569-598. doi:10.1146/annurev.psych.093008.100416

Hocevar, D. (1981). Measurement of creativity: Review and critique. Journal of Personality Assessment, 45(5), 450-464.

Jauk, E., Benedek, M., \& Neubauer, A. C. (2014). The road to creative achievement: a latent variable model of ability and personality predictors. European Journal of Personality, 28, 95-105.

Jesus, N., Rus, C. L., Lens, W., \& Imaginário, S. (2013). Intrinsic motivation and creativity related to product: A meta-analysis of the studies published wetween 1990-2010. Creativity Research Journal, 25(1), 80-84. doi:10.1080/10400419.2013.752235

Kasof, J., Chen, C., Himsel, A., \& Greenberger, E. (2007). Values and creativity. Creativity Research Journal, 19(2-3), 105-122. doi:10.1080/10400410701397164

Kaufman, J. C., \& Beghetto, R. A. (2009). Beyond big and little: The four c model of creativity. Reviere of General Psychology, 13(1), 1-12. doi:10.1037/a0013688.

Kenny, D. A. (2015). Mediation. Retrieved from http://davidakenny.net/cm/mediate.htm

Kyung, H. K. (2011). The creativity crisis: The decrease in creative thinking scores on the Torrance Tests of Creative Thinking. Creativity Research Journal, 23(4), 285-295.

Lange, B. P., \& Euler, H. A. (2014). Writers have groupies, too: High quality literature production and mating success. Evolutionary Behavioral Sciences, 8(1), 20-30. doi:10.1037/h0097246

Lebedeva N. M., \& Bushina E. V. (2015). Influence of personal values and motivation with creative behavior and attitude to innovations. Psikhologiya o Ekonomike $i$ Upravlenii [Psychology in Economics and Management], 7(1), 26-35. doi:10.17150/2225-7845.2015.7(1).26-35 (in Russian)

Leimgruber, P. (2011). Values and votes: The indirect effect of personal values on voting behavior. Swiss Political Science Review, 17(2), 107-127.

Mayakovskii, V. V. (1959). Kak delat' stikhi [How to make verses]. In V. V. Mayakovskii, Polnoe sobranie sochinenii [Collected works] (Vol. 12, pp. 81-117). Moscow: Khudozhestvennaya literatura. Retrieved from http://feb-web.ru/feb/mayakovsky/texts/ms0/msc/msc-081-.htm (in Russian)

Michael, H. (2016). How writers write: Exploring the unconscious fantasies of writers. Psychoanalytic Psychology, 33(1), 21-34, doi:10.1037/a0038957

Oganesyan, N. N. (2013). Praktikum po psikhologii tvorchestva [Seminars in psychology of creativity]. Moscow: Flinta. (in Russian)

Parks-Leduc, L., \& Guay, R. P. (2009). Personality, values, and motivation. Personality and Individual Differences, 47(7), 675-684. doi:10.1016/j.paid.2009.06.002

Prabhu, V., Sutton, C., \& Sauser, W. (2008). Creativity and certain personality traits: Understanding the mediating effect of intrinsic motivation. Creativity Research Journal, 20, 53-66. doi:10.1080/10400410701841955

Rettig, H. (2011). The 7 secrets of the prolific: The definitive guide to Overcoming procrastination, perfectionism, and writer's block. Infinite Art. 
Roccas, S., Sagiv, L., Schwartz, S. H., \& Knafo, A. (2008). The big five personality factors and personal values. Personality and Social Psychology Bulletin, 28, 789-801. doi:10.1177/0146167202289008

Runco, M. A. (2004). Creativity. Annual Review Psychology, 55, 657-87. doi:10.1146/annurev.psych.55.090902.141502

Schwartz, Sh. H. (2006). Basic human values: Theory, measurements and applications. Revue Francaise de Sociologie, 47(4), 249-288.

Schwartz, S. H. (2012). Basic personal values and political orientations. In J. H. Aldrich \& K. M. McGraw (Eds.), Improving public opinion surveys: Interdisciplinary innovation and the American national election studies (pp. 63-82). Princeton, NJ: Princeton University Press. doi:10.1515/9781400840298

Schwartz, S., Butenko, T. P., Sedova D. S., \& Lipatova, A. S. (2012). A refined theory of basic personal values: Validation in Russia. Psychology. Journal of Higher School of Economics, 9(2), 43-70. (in Russian)

Sharma, N. K., \& Rastogi, D. (2009). A multicriterial approach to creativity for realistic divergent thinking problems. Journal of the Indian Academy of Applied Psychology, 35(1), 9-16.

Sousa, C. M. P., \& Coelho, F. (2011). From personal values to creativity: evidence from frontline service employees. European Journal of Marketing, 45(7/8), 1029-1050. doi:10.1108/03090561111137598

Sternberg, R. J. (2006). The nature of creativity. Creativity Research Journal, 18(1), 87-98. doi:10.1207/s15326934crj1801_10

Volkenshtein, M. (1970). Stikhi kak slozhnaya informatsionnaya sistema [Poems as a complex information system]. Nauka i Zhizn', 1. Retrieved from http://www.lib.ru/NTL/ARTICLES/volkernsht.txt_with-big-pictures.html (in Russian)

Weinstein, E. C., Clark, Z., DiBartolomeo, D. J., \& Davis, K. (2014). A decline in creativity? It depends on the domain. Creativity Research Journal, 26(2), 174-184. doi:10.1080/10400419.2014.901082

Yagolkovskii, S. R. (2007). Psikhologiya kreativnosti i innovatsii [Psychology of creativity and innovations]. Moscow: HSE Publishing House. (in Russian)

Maria A. Bultseva - research intern, International Laboratory for Socio-Cultural Research, Expert Institute; Ph.D. student, School of Psychology, Faculty of Social Sciences, National Research University "Higher School of Economics".

Research area: psychology of creativity, cross-cultural psychology.

E-mail: bulceva@mail.ru

Nadezhda M. Lebedeva - head, International Laboratory for Socio-Cultural Research, Expert Institute; professor, Department of Psychology, Faculty of Social Sciences, National Research University "Higher School of Economics", D.Sc., professor.

Research area: ethnic and cross-cultural psychology, intercultural relations, acculturation of migrants, values transmission, creativity and innovation.

E-mail: nlebedeva@hse.ru 